\title{
Copper Ore Quality Tracking in a Belt Conveyor System Using Simulation Tools
}

\author{
Piotr Bardzinski, ${ }^{1}$ Leszek Jurdziak, ${ }^{1}$ Witold Kawalec $\odot,{ }^{1,2}$ and Robert Król ${ }^{1}$
}

\author{
Received 30 December 2018; accepted 26 April 2019 \\ Published online: 13 May 2019
}

The ore quality at mining faces in the KGHM underground copper ore mines can be determined based on channel samples and block models built in the Datamine system. Unfortunately, even very accurate information regarding the quality of deposits at mining faces does not translate into the possibility of predicting the composition of feed to enrichment plants. The mixed ore from mining faces is cyclically loaded by trucks onto belt conveyors, which in turn convey it to shafts. When transported on the conveyors, mixed ore portions from many loading points form a divisional stream, which then goes to the main haulage conveyors where ore streams from various divisions are combined. The way of filling the bunkers, as well as ore flow temporary stoppages, changes the sequence of ore mixing and its arrival, which hinders the ability to track its quality. In the current study, radiofrequency identification (RFID) was proposed for tracking ore composition. A complementary method of ore quality prediction comes from simulating the tagged ore flow within the FlexSim software package. The discrete element method (DEM) of simulations, verified by experiments with RFID tags, can determine the ore flow through bunkers. Forecasts of ore feed composition for the next shift can be prepared with actual plans of mining division operations, the filling level of bunkers and the work plan of the transport system.

KEY WORDS: Ore quality tracking, RFID, Datamine, FlexSim, DEM, Copper mine.

\section{INTRODUCTION}

The activities of the Poland-based mining enterprise KGHM Polska Miedz S.A. cover the full value creation chain. Deposit development includes exploration and assessment, ore extraction from its primary deposits and land rehabilitation, while processing involves ore enrichment, smelting and refining. In the first half of 2018, it produced 205 thousand $\mathrm{Mg}$ of copper in concentrate, $640 \mathrm{Mg}$ of silver in concentrate, $478 \mathrm{Mg}$ of metallic silver, as

\footnotetext{
${ }^{1}$ Faculty of Geoengineering, Mining and Geology, Wroclaw University of Science and Technology, Na Grobli St. 13/15, 50421 Wrocław, Poland.

${ }^{2}$ To whom correspondence should be addressed; e-mail: witold.kawalec@pwr.edu.pl
}

well as 171 and 56 thousand $\mathrm{Mg}$ of electrolytic copper from its own and purchased concentrate, respectively.

Nowadays, the management staff of the KGHM bases their control over the ore production on different unconnected sources. Data regarding lithology and ore grade at each mining block were stored in an online database called MOPRONA. The operators of crushing machines report the courses of haul trucks, while the belt scales under the nodes of the main haulage conveyors monitor the carried ore mass. Due to the dynamic situation in the mine, which involves the introduction of ore from sources with different lithologies, as well as its mixing in the pass-through bunkers and during its transport on the conveyors, qualitative information on the product is 
lost. This leads to the situation where the management staff can only predict future production based on its current or historical record.

The challenge is to integrate fully the flow of raw material, in this case the copper-bearing ore, into the global process control system of the mine and its processing facilities. It can give the management staff an understanding of, and thus control over the internal dynamics of mixing processes and emergent events, which have a direct influence on the ore quality and quantity at the output of a mine. This knowledge is crucial for the adjustment of the processing parameters to the current production in order to save energy and reduce wear of the crushing devices. It can also help the general managers make appropriate economic decisions about the exploitation of different ore deposits.

Worldwide attempts were made to apply time sequencing of discrete events to optimize various production processes (Shouqi et al. 2016; Si-Yu et al. 2017; Kierzkowski and Kisiel 2017; Zhou et al. 2017). Software packages utilizing this approach include Arena, Enterprise Dynamics, Plant Simulation, ProModel and FlexSim (Nordgren 2003; Lavery et al. 2005). The last was successfully used to model ore transport in open-pit mines (Libing et al. 2008; Chen and Shi 2017).

Radio-frequency identification (RFID) technology has found a broad range of applications in the mining sector. These applications include as intrusion detection system for identification of toxic gases in underground mines (Gautam and Om 2018), truck travel time measurement in an open-pit mine (Jung and Choi 2017; Baek et al. 2018), vehicle proximity detection for collision prevention (Baek and Choi 2018), mine operation management based on equipment and personnel tracking (Stolba et al. 2013; Jung and Choi 2016; Binguo et al. 2017), and tracking of explosives (Mahmad et al. 2016). The idea of ore marking with RFID tags was first proposed at the Vale Inco's copper-nickel ore FroodStobie mine (Fiscor 2007).

The current study shows an overview of mining activities in Polish copper mines, as well as a holistic solution to the tracking of ore provenance and its quality identification at the mine output. The work was conducted within the European Union's Horizon 2020 project Distributed In-Situ Sensors Integrated into Raw Material and Energy Feedstock (DISIRE), involving 15 research and industrial partners from six countries. Its ultimate goal was to achieve product-specific online adaptation of the control system that could be applied in different branches of industry. In our knowledge, such a solution, at least in the mining sector, has yet to be formulated.

The in situ experiment was conducted in the ZG Lubin copper mine. Ore portions from different parts of the mine, with various lithologies, were marked with RFID tags with ascribed qualitative and quantitative information. The flow time of the tags between each loading point and the process plant was recorded (Król et al. 2016; Jurdziak et al. 2017b; Bardzinski et al. 2018). FlexSim was chosen to build the model of the transport system of the underground copper mine in the current project, which was successfully tested by comparing the experimental RFID tag flow times. Rock material coming from the different loading points is mixed within the retention bunker, which affects its transport time. The problem was described using the discrete element method (DEM) and the EDEM software package (Kessler and Prenner 2009; Di Maio et al. 2009), which helped to adjust the model of the mine to the experimental RFID tag flow times. The major novelty of the proposed solution comes from the integration of the data collected from different databases involving the actual mine characteristics into one software-based system, which will give the management staff a useful tool for ore grade and lithology prediction.

\section{METHODS}

The aim of the study was to create a complex simulation model of the belt conveyor-based transport system of an actual Polish copper mine. The model was parameterized with the mined orebody data (lithology and quality), mining schedules, the operational time of vehicles supplying the ore from mining fields, the velocities of the system's parts, and discretized flow times of ore batches and RFID tags in the shaft ore bunker.

Ore samples, obtained by channel sampling, were prepared on HERZOG sample preparation lines and analyzed by Philips MagiX Pro, PW2540 and Axios X-ray fluorescence (XRF) spectrometers. The detailed procedure of channel sampling from drift faces in the ZG Lubin mine was discussed by Jurdziak et al. (2017a). Drillhole sampling, together with the georadar sampling method (GPR) applied in boreholes, was employed to investigate the lithological profile in a spatial manner. Then, three- 
dimensional modeling of the lithological profiles was performed utilizing the block modeling method for lithology wireframe estimation in the Datamine Studio software package. The data regarding lithology and ore grade at each mining block were stored in the MOPRONA system. RFID was used to mark the run-of-mine ore portions (Blazej et al. 2018).

Time sequencing of discrete events in the FlexSim package was used to build the model of the mine's transport system. The experimental run was set to five working days or 432,000 s. Each loading point is supplied by three haul trucks with a different mass-based loading capacity: 15, 12 and $8 \mathrm{Mg}$. The frequency of generating discrete ore portions by each of the three source types was based on their respective empirical histograms. The DEM based on Newton's second law and particle contact models (EDEM software package) was used to model the particle flow through the ore bunker.

\section{Case Study: Mining Activities Specification}

Drillhole and georadar sampling allow the lithological profile to be revealed, which is then spatially modeled in the Datamine Studio software package (Datamine 2018). Figure 1 shows an example cross section of the lithological profile across several pillars, indicating a spatial variation in lithology due to the orientation of the rock layers with respect to the actual floor and roof of the ore horizon. According to the data presented in Table 1, when new mining fields are excavated, the lithological contributions of each fraction are variable over time. This is due to the orientation of rock layers in three-dimensional space.

Mining works commence with channel sampling, followed by rock blasting at the mining front. The data are sent to the automated analytic system based on XRF spectrometers. Over 1000 samples can be automatically processed daily. The information about the contributions of each lithological fraction, as well as the pure metal content, is obtained and stored in the MOPRONA ${ }^{1}$ system, which is available online. As shown in Figure 1, the excavation profile, due to economic reasons, is often limited to the Kupferschiefer or most copper-rich black sedimentary shale together with surrounding

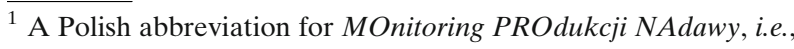
Ore Feed Production Monitoring.
}

dolomite and sandstone, which contain less, but still economically viable amounts of copper.

In all Polish copper mines, as shown in Figure 1, the room-and-pillar mining scheme is used. Technological pillars are left during the mining works ${ }^{2}$ in order to carry the compression forces of the orogen. Mining activities at each face commence with the production of the housing. On the mining face, the bolt holes are drilled and the bolts are installed. The loose ore is removed either mechanically or by hand. Then, blast holes are drilled and loaded. After that, the rock material is blasted with fire explosives, hauled by haulers or loaders and dropped at the loading points. The larger lumps of rocks are crushed, sieved and transported further by the belt conveyors, which convey the ore to the shafts. The ore is loaded cyclically from ca. 150 faces in each mine.

The main haulage conveyors transport the ore to the retention bunker-a large container carved in rock-through which the ore is flowing to the crushers through two output chutes. The mixing of ore during transport on the conveyors and within the retention bunker leads to the loss of the important geometallurgical information about the ore quality and provenience. Crusher chambers and shaft containers are located near the extraction shafts. The ore flowing through them is extracted to the surface with the use of hoisting skips. Finally, the ore is transported to the ore enrichment plant (termed simply as process plant in the text) by the belt conveyors. Copper recovery is performed within the froth flotation process, preceded by crushing, grinding and milling (Malewski 2017). The parameters of the latter three operations are dependent on the lithological composition of the ore. Tailings are managed by an extraction and waste neutralization facility located near the Zelazny Most tailings dam, which is the largest structure of this type in Europe.

\section{System Modeling}

As mentioned above, the ore coming from different sources mixes while on its transportation path and over time, and hence, even very accurate information about the quality of the deposit at the mining faces does not translate into the possibility of

\footnotetext{
${ }^{2}$ Or at least the ore is mined from the technological pillars when the mining works in the certain area are not planned to be continued.
} 


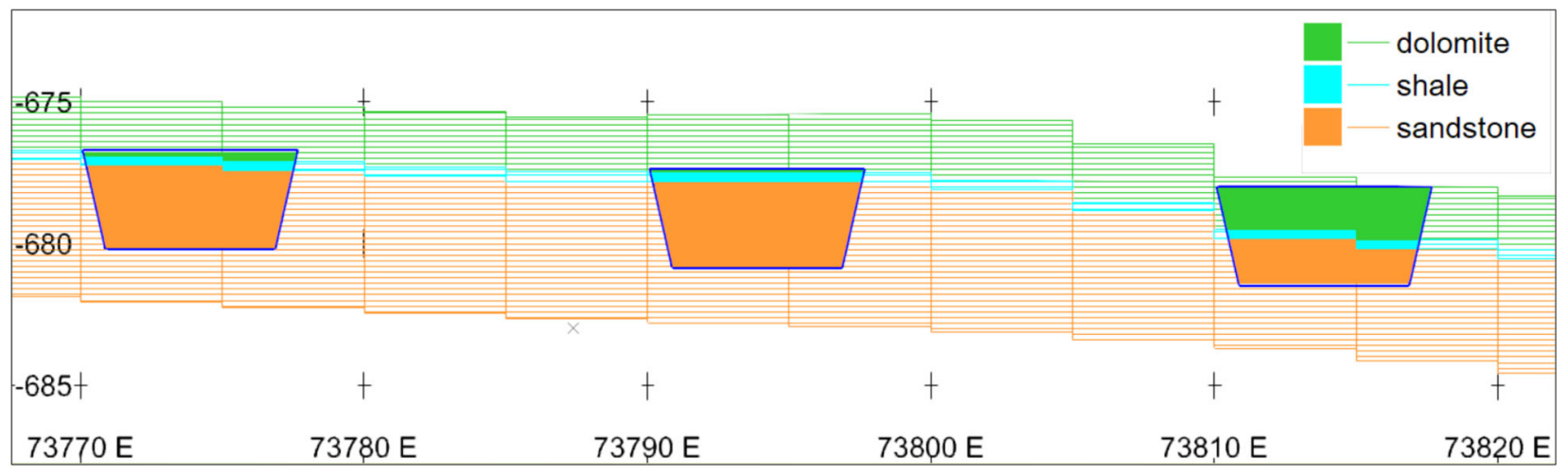

Figure 1. Visualization of a wireframe solid model of developments of a room-and-pillar mining system. The walls and roofs of the modeled drives are colored against the actual lithology of the intersected cells of the orebody block model; PL2000 and Kronstadt coordinate systems are given in meters.

Table 1. Time variability of the lithology of actual mining fields in three KGHM mines averaged over each whole mine

\begin{tabular}{|c|c|c|c|c|c|c|c|}
\hline \multirow{2}{*}{$\begin{array}{l}\text { Concentrator } \\
\text { name }\end{array}$} & \multirow{2}{*}{$\begin{array}{c}\text { Lithological frac- } \\
\text { tion } \\
\text { Years }\end{array}$} & \multicolumn{2}{|c|}{ Sandstone } & \multicolumn{2}{|c|}{ Shale } & \multicolumn{2}{|c|}{ Carbonates } \\
\hline & & $\begin{array}{c}1985-1991 \\
(\%)\end{array}$ & $\begin{array}{c}\text { 2009-2011 } \\
(\%)\end{array}$ & $\begin{array}{c}\text { 1985-1991 } \\
(\%)\end{array}$ & $\begin{array}{c}2009-2011 \\
(\%)\end{array}$ & $\begin{array}{c}1985-1991 \\
(\%)\end{array}$ & $\begin{array}{l}2009-2011 \\
\quad(\%)\end{array}$ \\
\hline$\overline{\text { Lubin }}$ & & 54 & 78 & 8 & 1 & 38 & 22 \\
\hline Polkowice & & 10 & 23 & 6 & 5 & 84 & 72 \\
\hline Rudna & & 43 & 54 & 5 & 12 & 51 & 34 \\
\hline
\end{tabular}

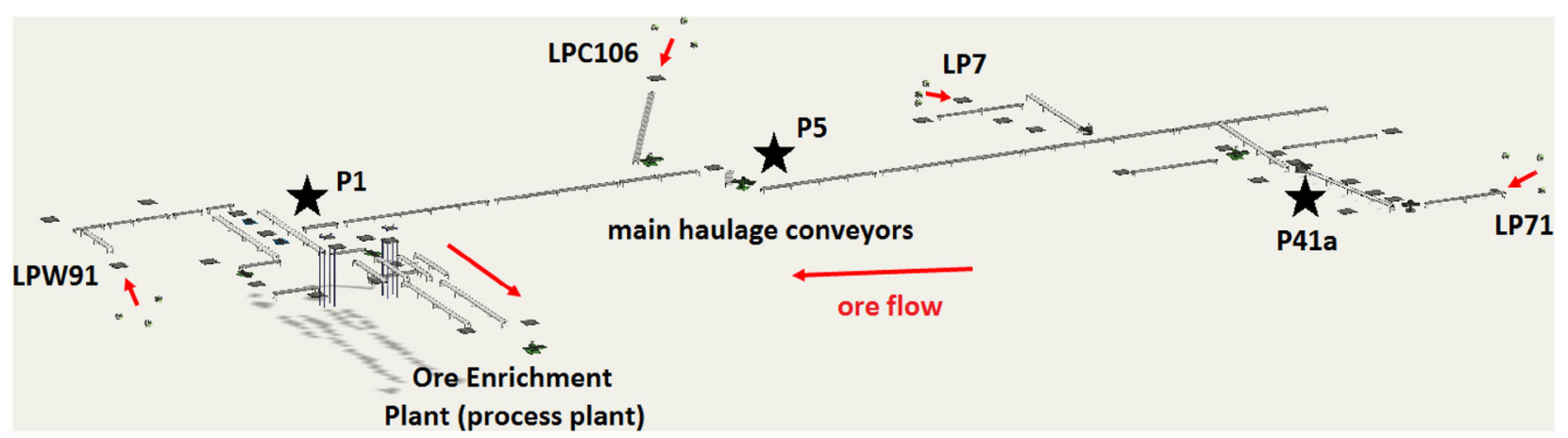

Figure 2. FlexSim model showing part of the ZG Lubin mine's transport system.

tracking the composition of the feed before it reaches the enrichment plants. For this reason, a solution can be found from combining big data sets of different types in order to create a model that could help in the qualitative and quantitative prediction of the most important parameters characterizing the ore.

First, the data that describe the mine transport system were collected. These contain the schedule of haul truck courses, which was different at each loading point. Based on oversized ore block crushing device operators' reports, the empirical distributions of haul truck courses with three loading capacities were derived. Workday schedules of skips and main haulage, as well as divisional haulage belt conveyors, contain their operational times and down times. The velocities of each of the conveyors were noted, together with the placement of the loading points and bunkers along the route of the conveyor. The lithology and copper content in the ore, acquired 
from the channel samples at each mining front, were taken from the MOPRONA ore production monitoring system. Ore portion discretization was conducted according to the loading capacity of each type of haul truck. The above-mentioned input information was included in the model of the ZG Lubin underground copper ore mine, which was built in FlexSim. Its graphical representation is shown in Figure 2, with the direction of ore flow indicated with arrows.

The active mining fields included in the simulation variants are listed in Table 2 . The corresponding ore lithology and grade in the actual case are based on the channel sample data from the MOPRONA database. In the current study, in order to represent the geological diversity of different mining fronts, lithological information was arbitrarily chosen and is shown in Table 3. The model can also track the variations in copper yield (Bardzinski et al. 2018, 2019), but the current study was limited to show changes in ore lithology.

Table 2. Loading points active in different simulation variants with the operational time given in days of the week ( $24 \mathrm{~h}$ each)

\begin{tabular}{lll}
\hline Simulation variant & Active loading points & Operational time \\
\hline 1A & LPW91 & Mo-Fr \\
& LPC106 & \\
& LP7 & \\
LP71 & \\
1B & LPW91 & Th-Fr \\
& LPC106 & We-Fr \\
& LP7 & Tu-Fr \\
& LP71 & Mo-Fr \\
1C & LPW91 & Th-Fri \\
& LPC106 & We-Fri \\
& LP7 & Tu-We \\
2 & LP71 & Mo-Tu \\
3 & LPW91 only & Mo-Fr \\
4 & LPC106 only & \\
5 & LP7 only & \\
\hline
\end{tabular}

\section{DESCRIPTION OF NUMERICAL CASE STUDIES AND RESULTS}

The output statistical information generated by the program involved the number of discrete ore portions transported from each of the mining faces, the total mass of transported material, and the ore lithology and grade after the transport path completion of ore portions from different sources that reached the process plant, which were recorded on an hourly basis. The results are presented in Figure 3. The total ore yield per hour in the whole mine is typically $434 \pm 9 \mathrm{Mg}$ with some zeroes and outbursts in the production. The latter followed the scheduled maintenance downtimes of the transport system and have been found to be caused by the ore storage in the bunkers together with short transport paths from the filled bunkers to the process plant, e.g., in the case of loading point LPW91.

In variant $1 \mathrm{a}$, all four loading points-each representing different lithologies and distant parts of the mine-were operating for five workdays. The ore stream is mixed at the process plant, producing the resulting composition that is approximately constant over time. Simulation variants V1b and V1c covered the unavailability of different ore sources. Such circumstances are common in a real mine, e.g., due to maintenance issues or staff decisions. Using the proper choice of operational times of the sources listed in Table 2, one could observe the gradual change of the lithological profile at the process plant, from sandstone dominant to dolomite dominant.

Such information could help crushing machine operators and process plant managers to adjust the ore processing parameters in advance if mining plans are known.

Variants V2-V5 show the situation of feeding the process plant with the material that comes from the single loading point. The dominant fraction in V2 is mostly dolomite, while in V4 it is sandstone. V3 and V5 are mixed cases with the domination of

Table 3. Lithology of ore delivered to different loading points

\begin{tabular}{|c|c|c|c|c|c|c|}
\hline \multirow[t]{2}{*}{ Localization in the mine } & \multicolumn{3}{|c|}{ Lithological contributions (\%) } & \multicolumn{3}{|c|}{ Copper content $(\%)$} \\
\hline & Sandstone & Shale & Dolomite & Sandstone & Shale & Dolomite \\
\hline LPW91 & 18.0 & 15.0 & 67.0 & 1.12 & 2.93 & 0.45 \\
\hline LPC106 & 20.0 & 35.0 & 45.0 & 0.32 & 3.15 & 1.23 \\
\hline LP7 & 89.7 & 10.3 & 0.0 & 0.77 & 2.31 & 0.00 \\
\hline LP71 & 71.0 & 22.0 & 7.0 & 0.66 & 1.32 & 1.96 \\
\hline
\end{tabular}



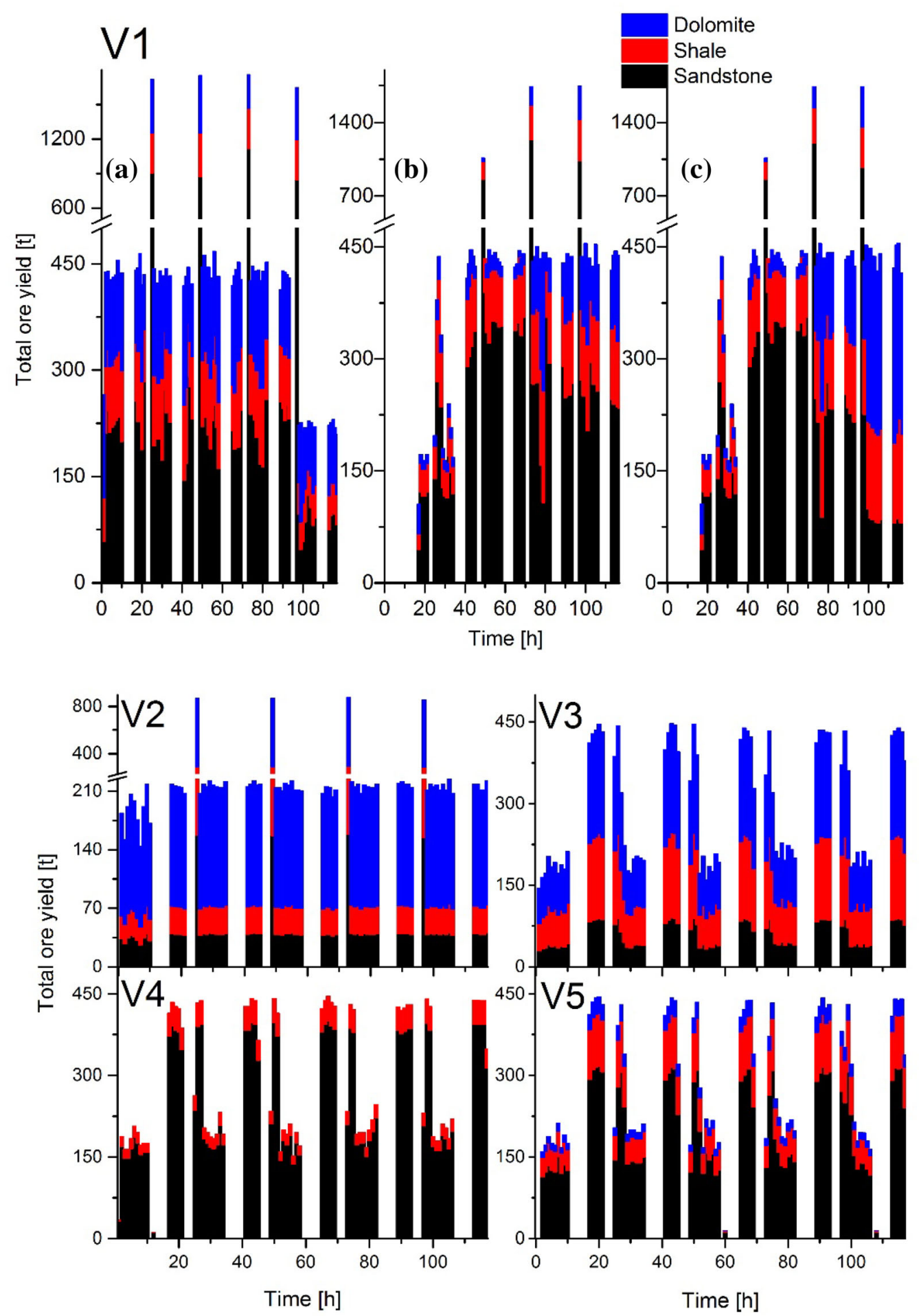

Figure 3. Ore lithology in different simulation variants. 
either of the mentioned fractions. In such cases, the changes in lithology of each source were found to produce a stable pattern, which was repeated over time. Note that while the primary lithology of the sources determined the dominant contributions at the process plant, the shape of the transported mass vs. time characteristics depends on the transport path.

\section{EXPERIMENTAL VERIFICATION OF THE MODEL}

In order to test the quality of the model, the experiment was conducted in the mine. RFID tags with the ascribed source number were dropped at three different loading points, marked as black stars in Figure 2. The tags were dropped in a defined time interval of $60 \mathrm{~s}$ and recorded by the acquisition device placed before the ore enrichment plant. Two types of RFID tags were used, which had smaller and bigger dimensions. Two reading antennae (separate for laboratory and industrial tests), 300 RFID tags of each of the two sizes (with a cost of about 2 Euro per tag), and the customization and implementation costs (Blazej et al. 2018) gave the total cost of the experiment of about 20,000 Euro. A single test conducted in the mine costs about 2000 Euro. According to Figure 4, the smaller tags probably were stuck in mud, so the flow times of their first portion were relatively longer. Most of the bigger ones travelled with the ore through its transport path, but were more prone to being damaged during crushing operations. The figure shows the mixing of the pellet in time and space, i.e., the distance from the dropping point and the process plant multiplied by the constant conveyor belt velocity of $2.5 \mathrm{~m} / \mathrm{s}$. Tags represented by data points placed above the dashed diagonal line were delayed with respect to their dropping time. Most of the tags

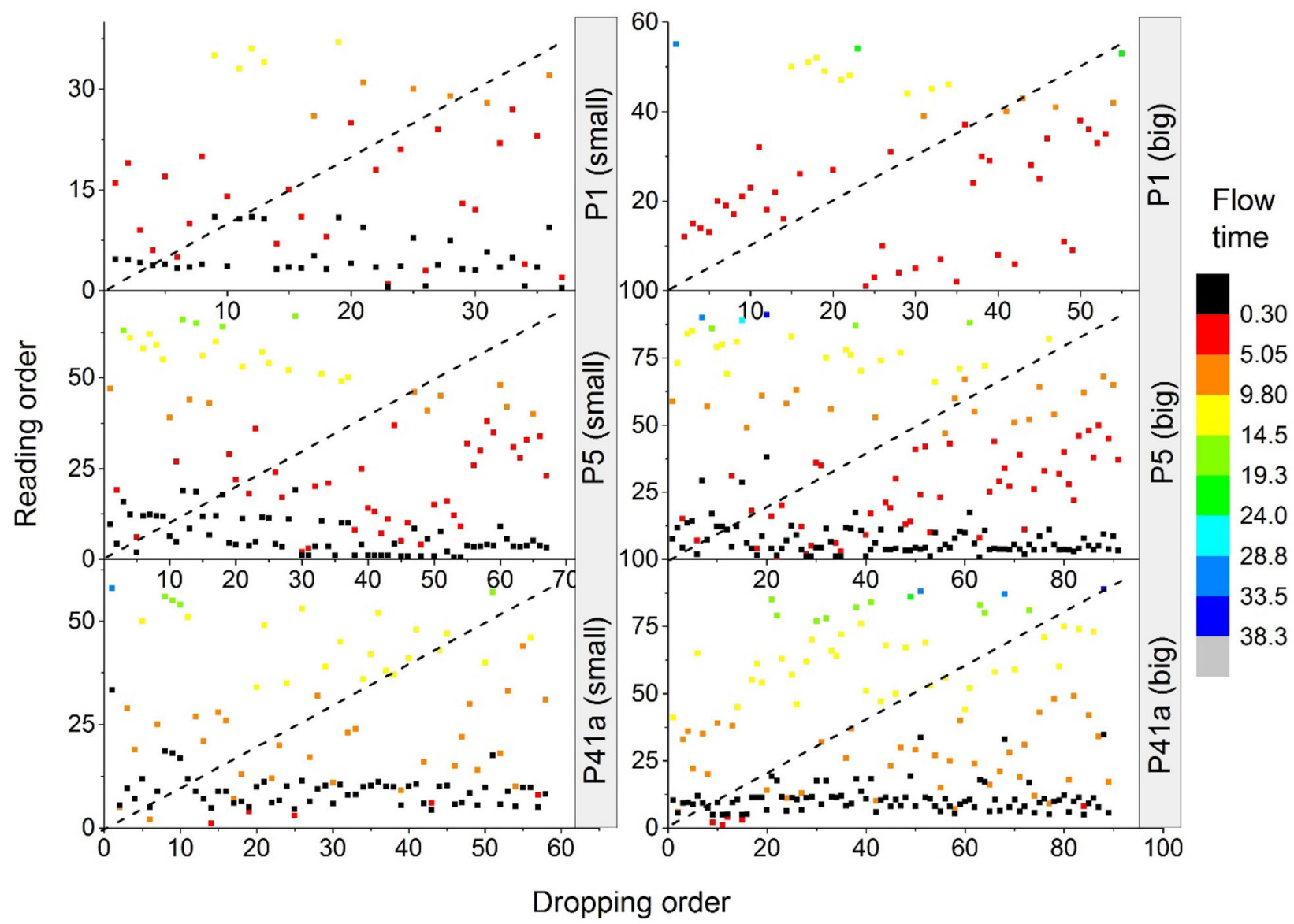

Figure 4. RFID tag drop-read statistics together with their flow times (given in hours) through the mine's transport system. 
arrived at the process plant in a different order than in which they were dropped. This indicates permutation or mixing and is most probably caused by the filling level of the ore bunker located downstream of the P41a dropping point. In order to maintain the operational continuity of the mine, the material is hauled from the bunker during ore source downtimes, which frequently occur on Saturdays and Sundays. Then, on Mondays, the bunker is almost empty. As the experiment was started on Monday, the first portions of the ore (as well as the RFID tags dropped first) were stuck in the bottom of the container, which explains their longer flow times (Bardzinski et al. 2018).

The flow time of the RFID tags between the dropping and detection points was compared with the simulations. It was found that the retention bunker placed before the crushers has a significant impact on the tag flow times. The DEM was adopted to study the discretized ore flow through this node of the transport system. According to observations, when the bunker content was above $70 \pm 10 \%$, the retention time of the ore portions is constant. For the two-chute and one-chute bunker discharges, two values of mean retention time were incorporated into the FlexSim model-80 and $120 \mathrm{~min}$, respectively. It was found that the one-chute bunker discharge variant of the FlexSim simulation complied well with the experimental time, while in the twochute variant the RFID tag flow times were shorter by about two hours (Bardzinski et al. 2018). Within the experiment, some of the RFID tags were crushed or stuck to the mud and would therefore never reach the process plant. Such a situation, based on the built-in random number generator algorithm (Law and Kelton 1991), was also modeled in FlexSim.

The model has the potential for further development. In the basic variants, the rock sources were infinite and the amount of excavated ore delivered to the loading point was controlled only by the haul truck inter-arrival times. Then, in our recent study (Bardzinski et al. 2019), the algorithm was developed to describe the situation where, during the blasting works, the rock debris from each lithological layer can fall in various ways. Within the algorithm, the amount of blasted rocks was fixed after each blasting works and the material is drawn in portions defined by haul truck shovel capacity up to the emptying of the rock piles of a certain type. Its application revealed an interesting feature, i.e., when more sandstone was drawn at the beginning, the depletion of its deposit in the subsequent haul truck courses occurred.

\section{CONCLUSIONS}

For more than 50 years, geologists, mathematicians, statisticians and geostatisticians have put a lot of effort in improving the methods of orebody modeling. After focusing on building the geologically proper structural orebody model and validated grade interpolation, more sophisticated orebody parameters (e.g., geometallurgical) were successfully modeled. However, all of these models relate to the in situ material, while investigations of raw material processing deal with the parameters of ore batches supplied to an ore enrichment plant. Unless these ore batches are identified with the previously recognized blocks of deposit in mining fields, the accuracy of an orebody model becomes irrelevant. When filling the existing information gap, ore tracking can be seen as the logical solution in order to utilize all the information of an orebody model for the more effective processing of raw material.

Therefore, the aim of the study was to demonstrate the complex approach to proper tracking of the provenience of the ore which travels through the belt conveyor system of a mine, and which then becomes mixed along its path to the ore enrichment plant. The example of the KGHM ZG Lubin underground copper mine was used to demonstrate that this goal can be reached when different simulation methods, such as discrete event simulation (FlexSim), the discrete element method (EDEM), orebody modeling (Datamine Studio) and RFID technology, are combined with various empirical data acquired from the mine. The tag experiment showed the occurrence of permutation (reversal) of the dropping-reading order of the RFID tags, which indicates the mixing of ore in time and space during its transport. In the transportation system simulation model, eight simulation variants were considered, which covered the unavailability of different ore sources. Such a situation occurs in a real mine, e.g., due to maintenance issues or the decisions of staff. The way it affects the contributions of lithologic fractions at the process plant was reflected in the obtained results. In the created model, it is possible to identify each ore batch loaded on the conveyor with a virtual tag carrying information about the ore composition, as well as to forecast the ore feed composition by simulating ore flow in the transport 
system. Any significant deviation from the plans requires the simulation to be restarted for new operating parameters of the system. The model can also be used to make economic decisions about further exploitation of each mining field, because it shows the contributions of each ore source to the total production of the metal, which was presented in previous studies (Bardzinski et al. 2018, 2019).

The ore tracking investigations originated from the work package "Non-ferrous mineral processing" in the DISIRE project (Król et al. 2016, Jurdziak et al. 2017b) and continued after the closure of the project (Bardzinski et al. 2018, 2019) because of interest of the industry. The improved operating control of mining production is a goal of KGHM, especially due to prices of copper dropping by some $30 \%$ since their peak in 2011. In the KGHM Lubin mine alone, recently applied organizational changes of controlled parameters of mining production (face advance instead of tonnage) have decreased dilution by some $10 \%$. Results from an effective ore tracking system would benefit and improve both production control (due to verified reconciliation of mine plans and to outputs achieved) and ore processing (especially ore grinding). The annual ore output of KGHM Polish mines is about 33 million Mg. Milling of this ore costs about 36 million Euros. Various proportions of ore lithological mix in ore batches cause a substantial dispersion of the specific energy of grinding (Król et al. 2016). Therefore, each 1\% (a conservative estimate) of an improvement in ore blending that enables energy consumption to be decreased might give savings of 0.36 million Euro/ year.

Optimized settings of crushing (grinding) and flotation (adjusted with regard to known processed ore lithology compounds) would also allow an increased $\mathrm{Cu}$ recovery from the processed ore of an estimated (conservatively) $0.03 \%$ (from 90 to $90.03 \%$ ). This is equal to some $140 \mathrm{Mg}$ of $\mathrm{Cu}$, which would return 0.83 million Euros. Other savings at KGHM could be expected due to the possibility of improving machinery equipment maintenance by obtaining accurate characteristics of transported ore streams (actual tonnage, ore lump dimensions and shape). The development of an ore tracking system seems to be well funded, and the company supports efforts toward its implementation.

\section{ACKNOWLEDGMENTS}

This article is partly funded by the statutory Grant of the Ministry of Science and Higher Education for Research No. 0401/0048/18.

\section{OPEN ACCESS}

This article is distributed under the terms of the Creative Commons Attribution 4.0 International License (http://creativecommons.org/licenses/by/4.0/), which permits unrestricted use, distribution, and reproduction in any medium, provided you give appropriate credit to the original author(s) and the source, provide a link to the Creative Commons license, and indicate if changes were made.

\section{REFERENCES}

Baek, J., \& Choi, Y. (2018). Bluetooth-beacon-based underground proximity warning system for preventing collisions inside tunnels. Applied Sciences, 8(11), 2271.

Baek, J., Choi, Y., Lee, C., \& Jung, J. (2018). Performance comparison of bluetooth beacon and reverse RFID systems as potential tools for measuring truck travel time in open-pit mines: A simulation experiment. Geosystem Engineering, 21(1), 43-52.

Bardzinski, P. J., Krol, R., Jurdziak, L., \& Kawalec, W. (2019). Random loading of blasted ore with regard to spatial variations of its actual lithological compound. In Anna Burduk, et al. (Eds.), Intelligent systems in production engineering and maintenance (pp. 668-677). Cham: Springer.

Bardzinski, P. J., Walker, P., Krol, R., \& Kawalec, W. (2018). Simulation of random tagged ore flow through the bunker in a belt conveying system. International Journal of Simulation Modelling, 17(4), 445-2018.

Binguo, W., Xuedong, D., Yongfa, H., \& Xiumei, X. (2017). Key issues and simulation of the internet of things of mine based on RFID technology. Agro Food Industry Hi-Tech, 28(3), 1143-1147.

Blazej, R., Kawalec, W., Konieczna, M., \& Krol, R. (2018). Laboratory tests on e-pellets effectiveness for ore tracking. Mining Science, 25, 21-31.

Chen, C., \& Shi, L. (2017). Simulating and optimizing of tramcar transportation attempter in open pit mine. In Gholami, M., Jiwari, R., \& Weller, K. (Eds.), Proceedings of the 2017 2nd international conference on modelling, simulation and applied mathematics (MSAM2017), volume 132 of advances in intelligent systems research (pp. 29-33).

Datamine software website (2018). February 01, 2019, https://ww w.dataminesoftware.com/resource-modelling/.

Di Maio, F. P., Di Renzo, A., \& Trevisan, D. (2009). Comparison of heat transfer models in DEM-CFD simulations of flu- 
idized beds with an immersed probe. Powder Technology, 193(3), 257-265.

Fiscor, S. (2007). Vale Inco tracks ore with RFID tags. Engineering and Mining Journal, 208(10), 52.

Gautam, S. K., \& Om, H. (2018). Intrusion detection in RFID system using computational intelligence approach for underground mines. International Journal of Communication Systems, 31(8), e3532.

Jung, J., \& Choi, Y. (2016). Collecting travel time data of mine equipments in an underground mine using reverse RFID systems. Tunnel and Underground Space, 26, 253-265.

Jung, J., \& Choi, Y. (2017). Analysis of tag recognition ranges and rates according to reader transmission power levels when tracking machines by RFID in underground mines: an indoor experiment. Geosystem Engineering, 20(2), 81-87.

Jurdziak, L., Kawalec, W., \& Kaszuba, D. (2017a). Identification of loading parameters for belt conveyors operating in KGHM's mines. In Proceedings 17th international multidisciplinary scientific GeoConference SGEM2017, chapter (Vol. 17, Issue 13, pp. 391-398).

Jurdziak, L., Kawalec, W., \& Król, R. (2017b). Study on tracking the mined ore compound with the use of process analytic technology tags. In International conference on intelligent systems in production engineering and maintenance 2017, Springer/Cham (pp. 418-427). https://doi.org/10.1007/978-3-3 19-64465-3 40.

Kessler, F., \& Prenner, M. (2009). DEM: Simulation of conveyor transfer chutes. FME Transactions, 37, 185-192.

Kierzkowski, A., \& Kisiel, T. (2017). A model of check-in system management to reduce the security checkpoint variability. Simulation Modelling Practice and Theory, 74, 80-98.

Król, R., Kawalec, W., Zimroz, R., Jurdziak, L., Jach, M., \& Pilut, R. (2016). Project DISIRE (H2020): An idea of annotating of ore with sensors in the KGHM PM S.A. underground copper ore mines. In Mineral engineering conference (MEC2016), E3S web of conferences 8, 01058. https://doi.org/10.1051/e3sc onf $/ 20160801058$.

Lavery, E., Nordgren, B., King, C., \& Hullinger, R. (2005). Flexsim modeling environment. In Z. Chen, X. Y. Peng, Z. G. Wang, H. B. Duan, W. H. Fan, N. Li, N. Li, J. Tan, S. Q.
Tang, P. Zhang, \& G. Zhao (Eds.), system simulation and scientific computing Proceedings (Vols. 1 and 2, pp. 16671670).

Law, A. M., \& Kelton, W. D. (1991). Simulation modeling and analysis (Vol. 2). New York: McGraw-Hill.

Libing, Y., Hanhong, C., Yuncai, C., \& Haiyang, Y. (2008). Simulating and optimizing of logistics system in strip mines. In: Proceedings 3 rd international symposium on modern mining \& safety technology proceedings (pp. 138-143).

Mahmad, M. K. N., Maz, M. R. R., \& Baharun, N. (2016). Applications of radio frequency identification (RFID) in mining industries. In IOP conference series: Materials science and engineering (Vol. 133, No. 1, p. 012050). IOP Publishing.

Malewski, J. (2017). Production of copper as a complex mining and metallurgical processing system in Polish copper mines of the Legnica-Glogów copper belt. In 2017 IOP conference series: earth and environmental science (vol. 95, p. 042005).

Nordgren, W. (2003). Flexsim simulation environment. In S. E. Chick, P. J. Sanchez, D. Ferrin, D. J. Morrice, editors. In Proceedings of the 2003 winter simulation conference (Vols. 1 and 2, pp. 197-200).

Shouqi, C., Ying, C., \& Chengming, C. (2016). Work Hours And Sorting Balancing Study of One Auto Mixed Line. In M. N. Tamin, \& R. Du (Eds.), 2016 international conference on mechanical, manufacturing, modelling and mechatronics (IC4 M 2016), volume 51 of MATEC web of conferences.

Si-Yu, C., Shu-Hai, F., Jia-Wei, X., \& Wen-Qian, Z. (2017). The design and development of flexsim/JMP based quality simulation system for mass customization. In P. Yarlagadda (Ed.), Proceedings of the 2016 international forum on mechanical control and automation (IFMCA 2016), volume 113 of AERadvances in engineering research (pp. 567-573).

Stolba, M., Jurco, T., \& Kebo, V. (2013). RFID technology in mining industry. International Multidisciplinary Scientific GeoConference: SGEM: Surveying Geology \& Mining Ecology Management, 1, 695.

Zhou, F. L., Wang, X., He, Y. D., \& Goh, M. (2017). Production lot-sizing decision making considering bottleneck drift in multi-stage manufacturing system. Advances in Production Engineering \& Management, 12(3), 213-220. 